\title{
BMJ Open Association between secondhand smoke exposure and blood lead and cadmium concentration in community dwelling women: the fifth Korea National Health and Nutrition Examination Survey (2010-2012)
}

To cite: Jung SY, Kim S, Lee $\mathrm{K}$, et al. Association between secondhand smoke exposure and blood lead and cadmium concentration in community dwelling women: the fifth Korea National Health and Nutrition Examination Survey (20102012). BMJ Open 2015;5: e008218. doi:10.1136/ bmjopen-2015-008218

- Prepublication history for this paper is available online. To view these files please visit the journal online (http://dx.doi.org/10.1136/ bmjopen-2015-008218).

SYJ and SuK are first authors and contributed equally.

Received 18 March 2015 Revised 26 June 2015 Accepted 30 June 2015

CrossMark

For numbered affiliations see end of article.

Correspondence to Dr Kiheon Lee; keyhoney@gmail.com

\section{ABSTRACT}

Objectives: To assess the association between secondhand smoke exposure and blood lead and cadmium concentration in women in South Korea.

Design: Population-based cross-sectional study. Setting: South Korea (Korea National Health and Nutrition Examination Survey V).

Participants: 1490 non-smoking women who took part in the fifth Korea National Health and Nutrition Examination Survey (2010-2012), in which blood levels of lead and cadmium were measured.

Primary outcome measures: The primary outcome was blood levels of lead and cadmium in accordance with the duration of secondhand smoke exposure.

Results: The adjusted mean level of blood cadmium in women who were never exposed to secondhand smoke was $1.21(0.02) \mu \mathrm{g} / \mathrm{L}$. Among women who were exposed less than $1 \mathrm{~h} /$ day, the mean cadmium level was $1.13(0.03) \mu \mathrm{g} / \mathrm{L}$, and for those exposed for more than $1 \mathrm{~h}$, the mean level was $1.46(0.06) \mu \mathrm{g} / \mathrm{L}$. In particular, there was a significant association between duration of secondhand smoke exposure at the workplace and blood cadmium concentration. The adjusted mean level of blood cadmium concentration in the never exposed women's group was less than that in the $1 \mathrm{~h}$ and more exposed group, and the $1 \mathrm{~h}$ and more at workplace exposed group: $1.20,1.24$ and $1.50 \mu \mathrm{g} / \mathrm{L}$, respectively. We could not find any association between lead concentration in the blood and secondhand smoke exposure status.

Conclusions: This study showed that exposure to secondhand smoke and blood cadmium levels are associated. Especially, there was a significant association at the workplace. Therefore, social and political efforts for reducing the exposure to secondhand smoke at the workplace are needed in order to promote a healthier working environment for women.

\section{Strengths and limitations of this study}

- This is the first study to show that women have elevated blood cadmium levels with increased exposure level to secondhand smoke (SHS), and there is a correlation between blood cadmium levels and the exposure level to SHS at work.

- We evaluated a nationally representative sample so that the results of our study would reflect characteristics of the general non-smoking female population in South Korea.

- We compared the exposure between home and workplace, which has not been evaluated concurrently in previous studies.

- Out study has several weaknesses: First, people who work in areas with higher chance of exposure to lead and cadmium were not considered. However, the number of women who work in such areas is very low in South Korea, so it is unlikely to have an effect on the research. Second, the survey was not conducted on metal intake through the consumption of food. However, daily exposure to cadmium and lead through food is low in South Korea.

\section{INTRODUCTION}

Exposures to secondhand smok (SHS) has been a major public health concern as it is causally linked to lung cancer, stroke, coronary heart disease, nasal irritation and harmful reproductive effects in women. ${ }^{1}$ There has been significant progress to reduce SHS exposure. However, nearly half $(46.4 \%)$ the non-smokers in the USA remain exposed. ${ }^{1}$ In South Korea, $4.9 \%$ of men and $16.7 \%$ of women were exposed to SHS at home and $55.2 \%$ of men and $37.2 \%$ of women were exposed to SHS at the workplace in $2011 .{ }^{2}{ }^{3}$ Overall, more than $30 \%$ of 
non-smoking adults and adolescents were still exposed to SHS in 2014 . $^{4}$ Smoke-free policies have shown incremental progress since 1995, but smoking is still permitted in many indoor public places. ${ }^{4}$

Cigarette smoke consists of mainstream smoke from the mouth during puffing and sidestream smoke from the lit end of the cigarettes between puffs. The sidestream smoke can reach deeper areas in the lung because the size and concentration of the particles are smaller and higher, respectively, than those of mainstream smoke. SHS is a mixture of sidestream smoke and exhaled mainstream smoke, ${ }^{5}$ and contains more than 4000 chemical compounds known to cause diseases, including nitrosamines, polycyclic aromatic hydrocarbons, cadmium, chromium, lead and nickel. ${ }^{5}{ }^{6}$ Lead and cadmium have been particular concerns due to their carcinogenicity, tendency to accumulate in the body and their potential toxicity to the developing fetus. ${ }^{78}$

There are strong associations between the blood lead levels and active smoking, as well as between blood cadmium levels and active smoking. ${ }^{9-11}$ Also, Leroyer et $a l,{ }^{12}$ and Lee and $\mathrm{Ha},{ }^{13}$ have proven the existence of a dose-response relationship in these associations, providing strong evidence that active smoking increases blood lead and cadmium levels. Richter et $a l^{14}$ found that urine lead levels among adults with high SHS exposure were similar to those of smokers, but the study was not considered, as it was based on the results from data adjusted only for creatinine and other various covariates, which might have influenced the results. Furthermore, there have only been a few studies that have revealed an association between SHS exposure and blood lead and cadmium, thus far.

This study was conducted to examine the association between SHS and blood lead and cadmium concentration while considering the possible confounding factors and to demonstrate how SHS at home and in the workplace can influence blood lead and cadmium levels differently in South Korean women.

\section{METHODS}

\section{Materials and methods}

Eligible participants are listed in figure 1. The Korea National Health and Nutrition Examination Survey V (KNHANES V; 2010-2012) was a nationwide survey representing the general South Korean population and included comprehensive information on the health status, health behaviours and sociodemographic characteristics of 25533 participants. A total of 1490 participants were included in this study in accordance with the eligibility criteria. The KNHANES V used a stratified multistage probability sampling so that the sampled population accurately represents the general population of South Korea. A total of 1490 participants represented the South Korean population of 9600000 . Since the survey data analysed are publicly available, this study was exempt from review by the Institutional Review Board.
SHS status was assessed among lifetime never-smokers, via a self-reported questionnaire. Then the participants were categorised into each group according to the duration of total exposure during a 1 day period $(0,>0$ to $<1$, and $\geq 1 \mathrm{~h})$, the duration of exposure at home $(0,>0$ to $<1$ and $\geq 1 \mathrm{~h}$ ) and the duration of exposure at the workplace $(0,>0$ to $<1$ and $\geq 1 \mathrm{~h})$. The participants were also asked if they had cohabiting family members who actively smoked (yes/no).

The urinary cotinine excretion is an index that reflects the degree of exposure to SHS as well as direct smoking. For the Korean National Health and Nutrition Examination Survey, urinary cotinine excretion was analysed using a gas chromatograph/mass spectrometer from PerkinElmer Clarus $600 \mathrm{~T}$ (PerkinElmer/Finland), which has a detection threshold of $0.28 \mathrm{ng} / \mathrm{mL}$. While a previous study has proposed a urinary cotinine level of $50 \mathrm{ng} / \mathrm{mL}$ as the cut-off value to differentiate between active smokers and non-smokers, ${ }^{15}$ this value has not been validated for Asians. Kang et $a l^{16}$ suggested that a urinary cotinine level of $\geq 100 \mathrm{ng} / \mathrm{mL}$ was an optimal value to distinguish never-smokers from active smokers in the South Korean population. The sensitivity and specificity of the criteria were $94.4 \%$ and $100 \%$, respectively. Kim and Jung ${ }^{17}$ supposed that a urinary cotinine level of $\geq 164 \mathrm{ng} / \mathrm{mL}$ also could be used to separate neversmokers from active smokers. The sensitivity and the specificity ranged from $87.1 \%$ to $93.8 \%$ and from $82.9 \%$ to $94.9 \%$, respectively. In our study, it was important to detect the association of SHS with lead and cadmium concentrations in the blood that were only influenced by SHS. Therefore, participants with a urinary cotinine level of $\geq 100 \mathrm{ng} / \mathrm{mL}$ were classified as current smokers due to the criteria having a higher specificity. In this study, current and past smokers were excluded through interviews and suspected current smokers, whose urinary cotinine concentration was above $100 \mathrm{ng} / \mathrm{mL}$, were also excluded.

Blood samples were obtained through a venipuncture, and lead and cadmium levels in the blood were measured by Graphite furnace atomic absorption spectrometry (GFAAS, AAnalyst AAS-600, Zeeman correction, Perkin Elmer, Singapore) performed by the Neodin Medical Institute. The laboratory equipment to detect blood lead and cadmium was controlled by using standard reference material from Whole Blood Metals Control (BIO-RAD, USA) for internal quality assurance, and the coefficient of variation for lead and cadmium levels was kept within $10 \%$. Additionally, external quality assurance satisfied G-EQUAS (German External Quality Assessment Scheme), which is a standard protocol to detect the presence of low dose chemicals. The detection limits of blood lead and cadmium levels from the equipment were 0.0223 and $0.087 \mu \mathrm{g} / \mathrm{dL}$, respectively, and all values detected were kept within the detection limit. ${ }^{18}$

The age of the participants was limited to 19 years and older. The residential area was classified based on Dong (city) and Eup (rural area) of the administrative district. 


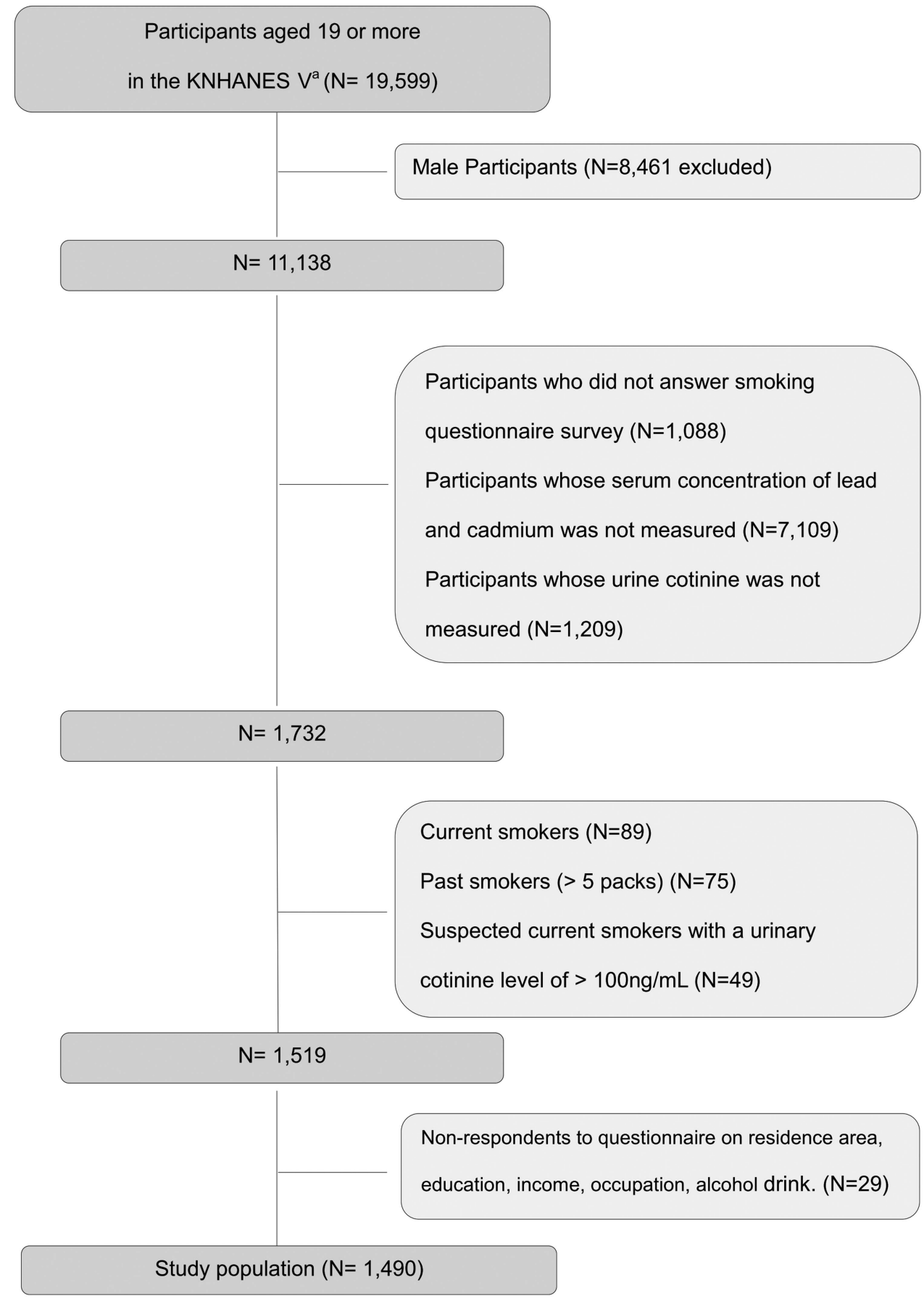

Figure 1 Study population (KNHANES V, Korea National Health and Nutrition Examination Survey V).

Occupation was divided into three broad categories: non-employed, blue collar workers and other workers. Other workers included agriculture, forestry and fishery workers, machine-operating assembly line workers and simple labourers, among others. Household income was divided into quartiles. Education was divided into four levels: below elementary school level, middle school graduate, high school graduate and college graduate or higher. Average daily alcohol consumption was calculated based on the total quantity per occasion and frequency of drinking in the past year, and divided into three categories: no alcohol intake, $0-9 \mathrm{~g}$ of alcohol and intake of $10 \mathrm{~g}$ or more. Alcohol intake frequency questions (alcohol intake frequency per month and the amount of alcohol consumption per occasion) were not open answer questions so the average value for each range was applied. We converted the amount of alcohol intake to pure alcohol content ( 1 glass=approximately $10 \mathrm{~g}$ ).

\section{Statistical analysis}

All analyses were performed using STATA statistical software V.13.0 (Stata Corp, College Station, Texas, USA). The 
differences in clinical characteristics according to SHS status were assessed using unpaired $t$ tests for the continuous variables and $\chi^{2}$ test for the discrete variables. We obtained a $p$ value for trend across categorical variables.

We assessed the associations between self-reported SHS status and urinary cotinine concentration to evaluate whether significant discrepancies existed between them. We used an analysis of variance model to determine the statistical differences in mean urinary cotinine according to each SHS status.

We conducted multiple linear regression analyses to calculate the adjusted means of lead and cadmium. We used the following covariates: age, residential area (rural/urban), education level, household income, alcohol intake and occupation. Lee and $\mathrm{Ha}^{13}$ proved that lead and cadmium concentrations increased with age and alcohol intake in the South Korean population. Shin et $a l^{19}$ showed that occupational class, family income and educational level could influence lead and cadmium concentrations in the blood for the South Korean population.

All analyses were weighted to the South Korean standard population from 2010 to 2012, which had reflected weights to the response rate, weights to sampling and weights to the population structure of the KNHANES parent study. A $p$ value $<0.05$ was considered significant, and we also displayed $95 \%$ CI.

\section{RESULTS}

\section{Baseline characteristics}

The sociodemographic characteristics and urinary cotinine concentration of the participants are presented in table 1 .

Among the total number of participants, $31.9 \%$ had been exposed to SHS. The mean age of the SHS-exposed group was significantly lower than that of the SHS-non-exposed group $(p<0.001)$. The mean urinary cotinine concentration of the SHS-exposed group was significantly higher than that of the SHS-nonexposed group $(\mathrm{p}<0.001)$. Residential area was not statistically different between the two groups. There were no consistent trends between educational level or family income and increased exposure to SHS. However, compared to participants with an educational level of elementary school or with the first quartile of family income, participants with an educational level of high school or with the third quartile of family income had higher tendency to be exposed to SHS with statistical significance (OR 1.84, $\mathrm{p}$ value 0.004 and $\mathrm{OR} 1.84, \mathrm{p}$ value 0.013 respectively). We found a consistent increase of SHS exposure as the amount of daily alcohol intake increased $(p<0.001)$. Compared to participants who were not employed, blue-collar workers and non-blue-collar workers had higher tendency to be exposed to SHS with statistical significance.

Table 1 Characteristics of study participants according to self-reported secondhand smoke (SHS) exposure ( $n=1490$, $\mathrm{N}=9.6 \mathrm{e}+06)$

\begin{tabular}{|c|c|c|c|}
\hline & $\begin{array}{l}\text { Never-smoker without SHS exposure } \\
n=1045,68.1 \%\end{array}$ & $\begin{array}{l}\text { Never-smoker with SHS exposure } \\
n=445,31.9 \%\end{array}$ & p Value \\
\hline Age, years & 50.15 (48.74 to 51.57 ) & 44.71 (42.40 to 47.02$)$ & $<0.001$ \\
\hline Urine cotinine, $\mathrm{ng} / \mathrm{mL}$ & $5.28(4.61$ to 5.96$)$ & $8.55(6.96$ to 10.13$)$ & $<0.001$ \\
\hline Residential area $(\%, 95 \% \mathrm{Cl})$ & & & 0.49 \\
\hline Urban & 77.57 (71.64 to 82.57$)$ & 79.65 (73.04 to 84.97$)$ & \\
\hline Rural & 22.43 (17.43 to 28.36$)$ & 20.35 (15.03 to 26.96$)$ & \\
\hline Education level (\%, 95\% Cl) & & & 0.017 \\
\hline$\leq$ Elementary school & 33.79 (29.70 to 38.14$)$ & 24.86 (19.22 to 31.50$)$ & \\
\hline Middle school & $11.13(8.92$ to 13.81$)$ & $10.48(7.38$ to 14.69$)$ & 0.38 \\
\hline High school & 28.98 (25.49 to 32.73$)$ & 39.12 (33.49 to 45.05$)$ & 0.004 \\
\hline$\geq$ College & 26.10 (23.04 to 29.41$)$ & 25.54 (21.10 to 30.56$)$ & 0.19 \\
\hline Family income (\%, 95\% Cl) & & & 0.011 \\
\hline 1 quartile (low) & 24.79 (20.93 to 29.11 ) & 19.33 (14.11 to 25.89 ) & \\
\hline 2 quartile & 26.92 (23.53 to 30.61$)$ & 21.15 (16.93 to 26.11$)$ & 0.97 \\
\hline 3 quartile & 22.83 (19.91 to 26.05$)$ & 32.78 (27.37 to 38.70$)$ & 0.013 \\
\hline 4 quartile & 25.45 (21.79 to 29.50$)$ & 26.73 (22.14 to 31.88$)$ & 0.20 \\
\hline Daily alcohol intake $(\%, 95 \% \mathrm{Cl})$ & & & $<0.001$ \\
\hline 0 (non-drinker) & 42.02 (37.64 to 46.54$)$ & 26.41 (20.86 to 32.82$)$ & \\
\hline $0-9 \mathrm{~g}$ & 54.06 (49.74 to 58.33$)$ & 62.40 (55.94 to 68.45$)$ & 0.001 \\
\hline$\geq 10 \mathrm{~g}$ & $3.91(2.77$ to 5.49$)$ & 11.19 (7.92 to 15.58$)$ & $<0.001$ \\
\hline Occupational class (\%, 95\% Cl) & & & $<0.001$ \\
\hline Non-employed & 57.84 (53.49 to 62.07 ) & 24.10 (18.69 to 30.49$)$ & \\
\hline Blue collar & $17.23(13.50$ to 21.74$)$ & 25.40 (19.69 to 32.12$)$ & $<0.001$ \\
\hline Others & 24.93 (22.12 to 27.97$)$ & $50.49(43.90$ to 57.07$)$ & $<0.001$ \\
\hline
\end{tabular}

Data are presented as the means and $95 \% \mathrm{Cl}$ or percentages and $95 \% \mathrm{Cl}$.

$\mathrm{p}$ Value from $\mathrm{t}$ test for continuous variables or $\chi^{2}$ test for categorical variables. 
Urinary cotinine concentration and self-reported

\section{SHS status}

Table 2 shows the total duration of SHS exposure was related to urinary cotinine $(\mathrm{p}<0.001)$.

The duration of exposure, both at work and at home, was related to urinary cotinine $(\mathrm{p}=0.007$ for at work; $\mathrm{p}=0.005$ for at home). Participants with cohabiting family members who actively smoked had a higher mean urinary cotinine concentration $(9.02 \mathrm{ng} / \mathrm{mL})$ than that of controls $(5.65 \mathrm{ng} / \mathrm{mL})$, with statistical significance.

\section{Lead and cadmium concentration according to self-reported SHS status}

Table 3 shows lead and cadmium concentrations in the blood compared to the duration of exposure to SHS.

No difference was observed in lead concentration according to SHS status, which was classified by the duration of exposure at workplace, exposure at home and total exposure. However, cadmium concentration in the blood differed depending on the exposure status. Compared to participants who were never exposed to SHS, participants who were exposed to SHS longer than $1 \mathrm{~h}$ at work or home, and total exposure, demonstrated higher cadmium concentration (1.20 vs 1.50 with $\mathrm{p}$ value $0.001 ; 1.21$ vs 1.45 with $p$ value $0.04 ; 1.21$ vs 1.46 with $p$ value $<0.0001)$. We found a consistent increase in cadmium concentration as the time of SHS exposure at

Table 2 Urinary cotinine concentration in relation to self-reported SHS environment

\begin{tabular}{|c|c|c|c|}
\hline Variables & $\mathbf{n}$ & $\begin{array}{l}\text { Cotinine } \\
\text { level }\end{array}$ & p Value \\
\hline $\begin{array}{l}\text { Total duration of passive } \\
\text { smoking per day }(\mathrm{h})\end{array}$ & 1490 & & $<0.001$ \\
\hline 0 & 1045 & $5.28(0.34)$ & \\
\hline$>0$ to $<1$ & 287 & $7.41(0.77)$ & \\
\hline$\geq 1$ & 158 & $10.46(1.62)$ & \\
\hline $\begin{array}{l}\text { Duration of passive } \\
\text { smoking at work per day } \\
\text { (h) }\end{array}$ & 1490 & & 0.007 \\
\hline 0 & 1178 & $5.62(0.33)$ & \\
\hline$>0$ to $<1$ & 239 & $8.44(1.15)$ & \\
\hline$\geq 1$ & 73 & $10.77(2.18)$ & \\
\hline $\begin{array}{l}\text { Duration of passive } \\
\text { smoking at home } \\
\text { per day }(\mathrm{h})\end{array}$ & 1490 & & 0.005 \\
\hline 0 & 1284 & $5.75(0.35)$ & \\
\hline$>0$ to $<1$ & 171 & $9.11(1.45)$ & \\
\hline$\geq 1$ & 35 & $9.38(1.55)$ & \\
\hline $\begin{array}{l}\text { Presence of family } \\
\text { members who actively } \\
\text { smoked }\end{array}$ & 1490 & & \\
\hline No & 1235 & $5.65(0.35)$ & 0.002 \\
\hline Yes & 255 & $9.02(1.07)$ & \\
\hline \multicolumn{4}{|c|}{$\begin{array}{l}\text { Data are presented as the means (SE). } \\
p \text { Value from ANOVA. } \\
p \text { Value from t test. } \\
\text { ANOVA, analysis of variance; } n \text {, unweig }\end{array}$} \\
\hline
\end{tabular}

work increased $(1.20,1.24$ and $1.50 \mu \mathrm{g} / \mathrm{L}, \mathrm{p}=0.005)$. No difference was found in lead and cadmium concentrations between participants living with active smokers, and participants not living with active smokers $(\mathrm{p}=0.79$ for lead and $\mathrm{p}=0.43$ for cadmium after adjusted for covariates).

\section{DISCUSSION}

In this study, we have demonstrated a significant association between blood cadmium concentration and SHS exposure in a large nationally representative sample. From an adjusted analysis, we found a consistent increase of blood cadmium concentration among participants who were exposed to SHS at workplaces. Additionally, we found that participants who were exposed to SHS for a longer duration than $1 \mathrm{~h}$ at home and at total exposure had higher blood cadmium concentration compared with participants who were never exposed to SHS. After adjusting for confounding factors that could influence blood concentration of the metals, we confirmed that regression coefficients of linear regression models were increased with statistical significance in the analyses of cadmium concentration of total SHS exposure and SHS exposure at workplaces. (Before adjustment, regression coefficient was 0.034 with $\mathrm{p}=0.313$. After adjustment, regression coefficient was 0.084 with $\mathrm{p}=0.006$; before adjustment, regression coefficient was 0.042 with $\mathrm{p}=0.30$. After adjustment, regression coefficient was 0.11 with $\mathrm{p}=0.005$.) That means the effects of exposure to SHS on cadmium concentration in the blood became more obvious after adjusting for confounders. No significant difference was found in the levels of lead and cadmium between participants living with smokers and those not living with smokers. (For lead $\mathrm{p}=0.79$ after adjustment, for cadmium $\mathrm{p}=0.43$ after adjustment.) Given the general circumstances in South Korea, having cohabiting smokers does not always suggest that participants will be exposed to SHS at home, as South Korean smokers usually smoke outdoors, usually on balconies, or in gardens or public outdoor spaces near home, and not indoors. Therefore, despite having cohabitants who are active smokers, participants might not be exposed to a significant amount of SHS in South Korea.

Several previous studies support the results of this work. Tobacco is well known as a notable source of cadmium and lead. ${ }^{20}$ Exposure to cigarette smoke via active and passive smoking was found to increase blood cadmium concentration among 158 workers in Israel. ${ }^{21}$ It was reported that urinary lead concentration was found to be increased according to SHS status in the US adult population. ${ }^{14}$ In Sweden, urinary cadmium concentration correlated with urinary cotinine concentration among 23 children with asthma. ${ }^{22}$

Studies on the relationship between SHS and lead concentrations in the blood have mainly been conducted with the participation of children as research subjects. It was found that lead concentrations in the 
Table 3 Association between self-reported SHS exposure and blood concentration of lead/cadmium in never-smokers

\begin{tabular}{|c|c|c|c|c|c|c|c|c|c|}
\hline \multirow[b]{2}{*}{ Variables } & \multirow{2}{*}{$\begin{array}{l}\text { Number } \\
\mathrm{n}\end{array}$} & \multicolumn{4}{|l|}{ Lead $(\mu \mathrm{g} / \mathrm{dL})$} & \multicolumn{4}{|l|}{ Cadmium ( $\mu \mathrm{g} / \mathrm{L})$} \\
\hline & & Crude mean & p Value & Adjusted mean & p Value & Crude mean & p Value & Adjusted mean & p Value \\
\hline $\begin{array}{l}\text { Total duration of passive smoking per } \\
\text { day }(\mathrm{h})\end{array}$ & 1490 & & 0.71 (overall) & & 0.55 (overall) & & 0.313 (overall) & & 0.006 (overall) \\
\hline 0 & 1045 & 2.02 (1.95 to 2.08$)$ & ref & 1.97 (1.91 to 2.04$)$ & ref & $1.26(1.21$ to 1.31$)$ & ref & $1.21(1.16$ to 1.25$)$ & ref \\
\hline$>0$ to $<1$ & 287 & 1.95 (1.84 to 2.06$)$ & 0.31 & 1.96 (1.86 to 2.07$)$ & 0.84 & $1.08(1.01$ to 1.16$)$ & $<0.001$ & $1.13(1.06$ to 1.19$)$ & 0.049 \\
\hline$\geq 1$ & 158 & 2.09 (1.97 to 2.21$)$ & 0.3 & 2.03 (1.91 to 2.16$)$ & 0.41 & 1.45 (1.32 to 1.60$)$ & 0.01 & 1.46 (1.35 to 1.58$)$ & $<0.001$ \\
\hline $\begin{array}{l}\text { Duration of passive smoking at work } \\
\text { per day }(\mathrm{h})\end{array}$ & 1490 & & 0.16 (overall) & & 0.10 (overall) & & 0.30 (overall) & & 0.005 (overall) \\
\hline 0 & 1178 & $2.00(1.93$ to 2.06$)$ & ref & $1.96(1.90$ to 2.16$)$ & ref & $1.25(1.20$ to 1.29$)$ & ref & $1.20(1.16$ to 1.24$)$ & ref \\
\hline$>0$ to $<1$ & 239 & 2.02 (1.92 to 2.13$)$ & 0.69 & 2.04 (1.93 to 2.15$)$ & 0.18 & $1.16(1.07$ to 1.25$)$ & 0.096 & $1.24(1.15$ to 1.34$)$ & 0.44 \\
\hline$\geq 1$ & 73 & 2.19 (1.98 to 2.40$)$ & 0.087 & 2.11 (1.90 to 2.32$)$ & 0.18 & 1.50 (1.32 to 1.68$)$ & 0.009 & $1.50(1.32$ to 1.68$)$ & 0.001 \\
\hline $\begin{array}{l}\text { Duration of passive smoking at home } \\
\text { per day }(\mathrm{h})\end{array}$ & 1490 & & 0.45 (overall) & & 0.63 (overall) & & 0.44 (overall) & & 0.13 (overall) \\
\hline 0 & 1284 & 2.02 (1.96 to 2.08$)$ & ref & 1.98 (1.93 to 2.04$)$ & ref & $1.24(1.20$ to 1.29$)$ & ref & $1.21(1.17$ to 1.25$)$ & ref \\
\hline$>0$ to $<1$ & 171 & 1.98 (1.85 to 2.10$)$ & 0.53 & $1.98(1.85$ to 2.10$)$ & 0.93 & 1.21 (1.10 to 1.32$)$ & 0.55 & 1.23 (1.13 to 1.33$)$ & 0.74 \\
\hline$\geq 1$ & 35 & 1.96 (1.71 to 2.22$)$ & 0.66 & 1.90 (1.66 to 2.14$)$ & 0.5 & 1.50 (1.18 to 1.83$)$ & 0.13 & 1.45 (1.23 to 1.67$)$ & 0.04 \\
\hline $\begin{array}{l}\text { Presence of family members who } \\
\text { actively smoked }\end{array}$ & 1490 & & 0.3 & & 0.79 & & 0.77 & & 0.43 \\
\hline No & 1235 & 2.02 (1.96 to 2.09$)$ & & 1.98 (1.93 to 2.04$)$ & & $1.25(1.21$ to 1.30$)$ & & $1.21(1.17$ to 1.25$)$ & \\
\hline Yes & 255 & 1.96 (1.86 to 2.07$)$ & & 1.97 (1.86 to 2.08$)$ & & $1.23(1.13$ to 1.33$)$ & & 1.25 (1.17 to 1.33$)$ & \\
\hline
\end{tabular}

All data are weighted to the residential population of South Korea.

Multiple linear analyses were used to calculate means adjusted for age, residential area, education, family income, daily alcohol intake and occupation.

Data are presented as the means $(95 \% \mathrm{Cl})$.

$\mathrm{p}$ Value from multivariate linear regression.

ref, reference value; SHS, secondhand smoke. 
blood increased as the number of smokers at home increased. ${ }^{23}$ Richter et $a l^{24}$ analysed blood lead level using NHANES 1999-2008 and found that higher exposure to SHS resulted in higher blood lead concentration. However, the result was more prominent in children and adolescents than in adults. In our study, we could not find any association between lead concentration in the blood and SHS exposure status. This may owe to the age range of our study population (44.71 years for those who were never exposed to SHS; 50.15 years for those who were exposed to SHS) being greater than the age range of adolescents or children. This can be explained by the fact that lead exposure comes largely from the general environment, including ambient air, diets and daily life activities. $^{25}$

Cadmium can enter the body through ingestion, inhalation and the skin. Between $10 \%$ and $50 \%$ of inhaled cadmium can be absorbed, and between $5 \%$ and $10 \%$ of ingested cadmium can be absorbed. The absorption of cadmium through the skin is negligible. The average cadmium concentration in the blood is twice as high in smokers as that in non-smokers. ${ }^{25}$ South Korean FDA (Food and Drug Administration) investigated the concentration of metals in foods available in South Korea. It announced that the total cadmium intake through all available foods was $10.4 \mu \mathrm{g} /$ day, which was $22.7 \%$ of PTMI (Provisional Tolerable Weekly Intake). Grain was attributed most to cadmium concentration, which was $22.9 \%$ of the total cadmium intake. Daily intake of cadmium in South Korea was similar to that in the USA, Britain, France and Germany, but lower than that in Japan, Australia and New Zealand. ${ }^{26}$ In South Korea, cadmium exposure of those over the age of 10 years was lower than the level recommended by Center for Disease Control, Commission on Human Biological Monitoring (CHBM), WHO and Environmental Protection Agency (EPA). ${ }^{27}$ Therefore, additional exposure to cadmium, by direct or passive smoking, is critical because it can increase the risk in disease processes caused by the metal, which could be preventable. Cadmium is classified as a human carcinogen by the Interactional Agency for Research on Cancer. Cadmium may be one of the risk factors for cardiovascular mortality and the deterioration of renal function. Moreover, the level of cadmium is critical for postmenopausal and premenopausal women because osteoporosis, osteomalacia and bone fracture caused by cadmium occur mainly among postmenopausal women, in addition to potential teratogenicity. ${ }^{25} 28$

South Korea has not yet implemented the comprehensive ban on indoor smoking in public places and workplaces recommended in the FCTC (Framework Convention on Tobacco Control) Guidelines. Smoking indoors in workplaces has decreased from $47 \%$ of smokers in 2005 to $32 \%$ in 2010 . However, the decrease was less significant compared with other countries where smoking in workplaces has decreased to less than $10 \%$ after implementation of the ban on indoor smoking.
The level of observed smoking in indoor workplaces was higher than other high-income ITC (International Tobacco Control) countries such as the USA, France, Canada, Ireland and Australia, and higher than middle-income ITC countries such as Mexico, Malaysia and Brazil. ${ }^{29}$ Furthermore, a ban on smoking in homes has been significantly less implemented in South Korea than in the USA. ${ }^{30}$ Cadmium is especially harmful to women due to its potential catastrophic effects to the fetus. Thus, emphasis must be placed on a social dimension regarding the dangers of SHS in order not only to prevent cancer, cardiovascular diseases and respiratory diseases, but also to prevent increased concentration of cadmium in the blood.

\section{Limitations}

Our study has several limitations. First, people who work in areas with higher chance of exposure to lead and cadmium were not considered. However, the number of women who work in such areas is very low in South Korea, so it is unlikely to have an effect on the research. Second, the accumulation of metals in the blood is a long-term process. Variables such as exposure to SHS used in this study are evaluated at the present time. This can bias the results. Third, the study was based on a selfadministered questionnaire about the exposure to SHS used as a proxy variable reflecting the SHS exposure status. This can lead to biased results. Lastly, the survey was not conducted on metal intake through the consumption of food. Although daily exposure to cadmium and lead through food is low in South Korea, further studies are needed to show their exact relationships.

Despite these limitations, our study has several strengths. We evaluated a nationally representative sample so the results of our study would reflect characteristics of the general non-smoking female population in South Korea. Additionally, we compared the exposure between home and workplace, which has not been evaluated concurrently in previous studies.

\section{Conclusions}

In this study, we showed that women had elevated blood cadmium levels after increased exposure to SHS, and there was a correlation between blood cadmium levels and the exposure level to SHS at work. This suggests that we need to further evaluate the effect of reduced exposure to SHS on the levels of cadmium in the blood. Even low blood levels of accumulated metals can be harmful to the human body. This study suggests the need for social and political efforts to reduce SHS exposure to promote healthy workplaces for women.

\section{Author affiliations}

${ }^{1}$ Department of Family Medicine, Seoul National University College of Medicine and Seoul National University Bundang Hospital, Seongnam, Gyeongi-do, Korea

${ }^{2}$ Department of Family Medicine, Seoul National University Hospital, Seoul, Korea 
${ }^{3}$ Health Promotion Center, Seoul National University Bundang Hospital, Seongnam, Gyeongi-do, Korea

Acknowledgements The authors would like to thank the members of the Korea Institute for Health and Social Affairs, who conducted the national survey, and all those who contributed to this project and Medical Research Collaborating Center (MRCC) at Seoul National University Bundang Hospital.

Contributors SYJ and SuK designed the study, analysed the data and drafted the manuscript as first authors. JYK, WKB, KL, J-SH and SaK contributed to the discussion and reviewed the manuscript. $\mathrm{KL}$ supervised the study as the corresponding author.

Funding This study was supported by a grant (number 02-2013-094) from the Seoul National University Bundang Hospital Research Fund.

Competing interests None declared.

Ethics approval Institutional Review Board of Seoul National University Bundang Hospital.

Provenance and peer review Not commissioned; externally peer reviewed.

Data sharing statement KNHANES V dataset is publicly available in South Korea and any requests for analyses will be received on the website: https:// knhanes.cdc.go.kr/knhanes/index.do.

Open Access This is an Open Access article distributed in accordance with the Creative Commons Attribution Non Commercial (CC BY-NC 4.0) license, which permits others to distribute, remix, adapt, build upon this work noncommercially, and license their derivative works on different terms, provided the original work is properly cited and the use is non-commercial. See: http:// creativecommons.org/licenses/by-nc/4.0/

\section{REFERENCES}

1. National Center for Chronic Disease P, Health Promotion Office on $S$, Health. Reports of the Surgeon General. The Health Consequences of Smoking-50 Years of Progress: A Report of the Surgeon General. Atlanta, GA: Centers for Disease Control and Prevention (US), 2014

2. Choi SH. Smoking status of adults and adolescents in Korea Secondary smoking status of adults and adolescents in Korea 2011. http://www.cdc.go.kr/CDC/cms/content/84/21484_view.html

3. Choi S, Park S, Lee J, et al. Trends in cigarette smoking among adolescents and adults in South Korea. Epidemiol Health 2014;36: e2014023.

4. Cho HJ. The status and future challenges of tobacco control policy in Korea. J Prev Med Public Health 2014;47:129-35.

5. Narkowicz S, Polkowska Z, Kielbratowska B, et al. Environmental tobacco smoke: exposure, health effects, and analysis. Crit Rev Environ Sci Technol 2013;43:121-61.

6. U.S. Department of Health and Human Services. The health consequences of involuntary exposure to tobacco smoke: a report of the surgeon general. Atlanta, GA: US Department of Health and Human Services, Centers for Disease Control and Prevention, Coordinating Center for Health Promotion, National Center for Chronic Disease Prevention and Health Promotion, Office on Smoking and Health, 2006;709.

7. Werler MM. Teratogen update: smoking and reproductive outcomes. Teratology 1997;55:382-8

8. Thompson J, Bannigan J. Cadmium: toxic effects on the reproductive system and the embryo. Reprod Toxicol 2008:25:304-15

9. Brockhaus A, Freier I, Ewers U, et al. Levels of cadmium and lead in blood in relation to smoking, sex, occupation, and other factors in an adult population of the FRG. Int Arch Occup Environ Health 1983;52:167-75.

10. Elinder CG, Kjellstrom T, Lind B, et al. Cadmium exposure from smoking cigarettes: variations with time and country where purchased. Environ Res 1983;32:220-7.
11. Watanabe $\mathrm{T}$, Kasahara $\mathrm{M}$, Nakatsuka $\mathrm{H}$, et al. Cadmium and lead contents of cigarettes produced in various areas of the world. Sci Total Environ 1987;66:29-37.

12. Leroyer A, Hemon D, Nisse C, et al. Environmental exposure to lead in a population of adults living in northern France: lead burden levels and their determinants. Sci Total Environ 2001;267:87-99.

13. Lee B, Ha J. The effects of smoking and drinking on blood lead and cadmium levels: data from the fourth Korea National Health and Nutrition Examination Survey. Korean J Occup Environ Med 2011;23:31-41.

14. Richter PA, Bishop EE, Wang J, et al. Tobacco smoke exposure and levels of urinary metals in the U.S. youth and adult population: the National Health and Nutrition Examination Survey (NHANES) 19992004. Int J Environ Res Public Health 2009;6:1930-46.

15. Goniewicz ML, Eisner MD, Lazcano-Ponce E, et al. Comparison of urine cotinine and the tobacco-specific nitrosamine metabolite 4-(methylnitrosamino)-1-(3-pyridyl)-1-butanol (NNAL) and their ratio to discriminate active from passive smoking. Nicotine Tob Res 2011;13:202-8.

16. Kang YH, Lee YJ, Kim HK, et al. Usefulness of urinary cotinine test to distinguish smokers from nonsmokers. Korean $J$ Lab Med 2003;23:92-7.

17. Kim S, Jung A. Optimum cutoff value of urinary cotinine distinguishing South Korean adult smokers from nonsmokers using data from the KNHANES (2008-2010). Nicotine Tob Res 2013:15:1608-16.

18. Lee B, Ha J. The effects of smoking and drinking on blood lead and cadmium levels: data from the fourth Korea national health and nutrition examination survey. Occup Environ Med 2011;68(Suppl 1): A93.

19. Shin JY, Kim JM, Kim Y. The association of heavy metals in blood, fish consumption frequency, and risk of cardiovascular diseases among Korean adults: the Korean National Health and Nutrition Examination Survey (2008-2010). Korean J Nutr 2012;45:347-61.

20. Ashraf MW. Levels of heavy metals in popular cigarette brands and exposure to these metals via smoking. ScientificWorldJournal 2012;2012:729430.

21. Shaham J, Meltzer A, Ashkenazi R, et al. Biological monitoring of exposure to cadmium, a human carcinogen, as a result of active and passive smoking. J Occup Environ Med 1996;38:1220-8.

22. Willers S, Gerhardsson L, Lundh T. Environmental tobacco smoke (ETS) exposure in children with asthma-relation between lead and cadmium, and cotinine concentrations in urine. Respir Med 2005;99:1521-7.

23. Apostolou A, Garcia-Esquinas E, Fadrowski JJ, et al. Secondhand tobacco smoke: a source of lead exposure in US children and adolescents. Am J Public Health 2012;102:714-22.

24. Richter PA, Bishop EE, Wang J, et al. Trends in tobacco smoke exposure and blood lead levels among youths and adults in the United States: the National Health and Nutrition Examination Survey, 1999-2008. Prev Chronic Dis 2013;10:E213.

25. Nordberg GF, Fowler BA, Nordberg M, et al. Handbook on the toxicology of metals. Academic Press, 2011.

26. Kim SH. Investigation of food metals in food and risk asseement in S.Korea. Secondary Investigation of food metals in food and risk asseement in S.Korea. 2011. http://m.mfds.go.kr/jsp/livinginfo_v.jsp? site_code $=1$ \&board_code $=31 \&$ seq $=16682 \&$ page $=31 \&$ searchText $=$

27. Roh SJ. Concentration of blood heavy metal monitoring in the fifth Korea National Health and Nutrition Examination Survey (KNHANES, 2010). Secondary Concentration of blood heavy metal monitoring in the fifth Korea National Health and Nutrition Examination Survey (KNHANES, 2010). 2010.

28. Kim KH, Lee CM, Park SM, et al. Secondhand smoke exposure and osteoporosis in never-smoking postmenopausal women: the Fourth Korea National Health and Nutrition Examination Survey. Osteoporos Int 2013;24:523-32.

29. Seo HG. ITC Korea National Report Waves 1 to 3 (2005-2010). Secondary ITC Korea National Report Waves 1 to 3 (2005-2010). 2012. http://www.itcproject.org/resources/view/1139

30. Ayers JW, Hofstetter CR, Hughes SC, et al. Smoking on both sides of the pacific: home smoking restrictions and secondhand smoke exposure among Korean adults and children in Seoul and California. Nicotine Tob Res 2010;12:1142-50. 